\title{
Development and Optimisation of Cassava Starch-Zinc-Nanocomposite Film for Potential Application in Food Packaging
}

\section{Fadeyibi A $^{1 *}$, Osunde $Z^{2}$, Agidi ${ }^{2}$, Idah PA² $^{2}$ and Egwim EC 3}

${ }^{1}$ Department of Agricultural and Biological Engineering, Kwara State University, Malete, Ilorin, Nigeria

${ }^{2}$ Department of Agricultural and Bioresources Engineering, Federal University of Technology, Minna, Nigeria

${ }^{3}$ Department of Biochemistry, Federal University of Technology, Minna, Nigeria

\begin{abstract}
The improvement of biodegradable film used in the food packaging has been made possible through nanotechnology. This research was carried out to develop and optimize the cassava starch-zinc-nanocomposite films for potential applications in food packaging. The zinc nanoparticles were prepared by sol-gel method and established with the particle sizes ranging from $4 \mathrm{~nm}$ to $9 \mathrm{~nm}$. The films were developed by casting the solutions of $24 \mathrm{~g}$ cassava starch, $0 \%$ to $2 \%$ (w/w) zinc nanoparticles and $45 \%$ to $55 \%(\mathrm{w} / \mathrm{w})$ glycerol in plastic mould of 8,10 and $12 \mathrm{~mm}$ depths. The average thickness of the films varied respectively with the depth as $15.14 \pm 0.22,16.21 \pm 0.36$ and $17.38 \mu \mathrm{m} \pm 0.13 \mu \mathrm{m}$. Permeability and stability of the films were determined at $27^{\circ} \mathrm{C}$ and $65 \%$ relative humidity and thermal range of $30^{\circ} \mathrm{C}$ to $950^{\circ} \mathrm{C}$, respectively. Also, the mechanical properties were determined using the nano indentation technique. The films were optimised based on their characterized attributes using their desirability functions. The hardness, creep, elastic and plastic works, which determined the plasticity index of the films, decreased with thickness and zinc nanoparticles. The water vapour permeability increased with the concentrations of glycerol, zinc nanoparticles and thickness while the oxygen permeability decreased with the nanoparticles. The degradations of the Nanocomposites at $100^{\circ} \mathrm{C}$ were in the range of $2 \%-3 \%$, which may indicate that the films are thermally stable. The optimum film whose desirability function is closer to the optimisation goal gave values of $49.29 \%$ glycerol, $17 \mu \mathrm{m}$ thickness and $2 \%$ zinc nanoparticles for maximum thermal and mechanical properties. The low permeability, high thermal stability and low plastic work at higher concentration of zinc nancomposites may be essential in food packaging.
\end{abstract}

Keywords: Starch-zinc nanocomposite; Permeability; Thermal stability; Mechanical properties; Optimisation

\section{Introduction}

The study of the control of organic or inorganic matter at dimensions of roughly $1 \mathrm{~nm}$ to $100 \mathrm{~nm}$ is termed nanotechnology. The addition of nanoparticles to renewable materials like starch and protein results in the formation of nanocomposite materials often transformed into flexible films [1-4]. The techniques involved in actualising this transformation are well understood, but their application in the food industry is greatly limited due to their poor service performance, especially in prolonging the shelf-life of food [5]. It is expected that the shelf-life of food should be improved by the addition of nanoparticles to flexible films, yet many nanocomposite materials are still unable to meet this packaging requirement [6,7] The addition of zinc nanoparticles as fillers to flexible films has proven quite promising due to their gas scavenging and antimicrobial activities, especially against gram-positive and gram-negative bacteria [8-10].

The thermal, mechanical and barrier properties of nanocomposite materials, which determined their suitability for packaging application, have been studied [6,11-16]. Zeng et al. [11], Taghizadeh and Sabouri [12] reported that the platelet nature of the nanoparticles usually hinders the diffusion of gases and specifically contributes to the improvement of their thermal and mechanical properties. Also, Huang and $\mathrm{Yu}$ [13] noted that introducing inorganic particles improved the thermal stability and mechanical resistance of starch-montmorilonite nanocomposite. The addition of chitosan in starch biofilms increased the thermal stability and ultraviolet absorption of the films [14-16]. Azeredo et al. [6], who carried out a study on the nanocomposite edible films from mango puree reinforced with cellulose nanofibre, revealed that the addition of the cellulose nanofibre significantly improved the thermal and mechanical properties of the films. However, most of the researches did not consider the antimicrobial and barrier scavenging potentials of the nanocomposite materials, especially the roles of the nanoparticles in actualising these. Also, the methods presented in synthesising the nanoparticles are quite expensive. Besides, the materials are not environmentally friendly and are generally toxic to human cells, thus limiting their potential application in food packaging. Hence, there is the desire for an alternative nanocomposite packaging material which is cheap to synthesize, environmentally friendly and has strong potential for antimicrobial and barrier scavenging activities, higher mechanical strength and thermal stability.

An excellent example of nanocomposite material with such desired packaging requirements is the one blended with zinc nanoparticles $[9,10]$. Unfortunately, the studies on such material have not been reported in the literature. The effects of thickness of the material, zinc nanoparticles and glycerol concentration, which is often added as plasticizer, have not been studied. Also, the information on the optimisation of the experimental variables leading to the development of suitable flexible films for food packaging has not been reported. There is therefore the need to fill the existing knowledge gap by undertaking the present study. The objective of this research was to develop and

*Corresponding author: Fadeyibi A, Department of Agricultural and Biological Engineering, Kwara State University, Malete, Ilorin, Nigeria, Tel: 234-0-7034867681; E-mail: adeshinaf601@gmail.com

Received April 18, 2016; Accepted May 09, 2016; Published May 16, 2016

Citation: Fadeyibi A, Osunde ZD, Agidi G, Idah PA, Egwim EC (2016) Development and Optimisation of Cassava Starch-Zinc-Nanocomposite Film for Potential Application in Food Packaging. J Food Process Technol 7: 591. doi:10.4172/2157. 7110.1000591

Copyright: ( 2016 Fadeyibi A, et al. This is an open-access article distributed under the terms of the Creative Commons Attribution License, which permits unrestricted use, distribution, and reproduction in any medium, provided the original author and source are credited. 
optimize the cassava starch-zinc-nanocomposite film based on their barrier, thermal and mechanical properties for use in food packaging.

\section{Materials and Methods}

\section{Preparation of cassava starch}

Freshly harvested gari cultivar cassava tubers $(5 \mathrm{~kg})$, obtained from Kasuwan, Gwari Market in Minna, Niger State was used to prepare the starch. The produce was pealed and soaked in a clean bowl containing water for 24 hours after which it was ground into pastes. The ground paste was sieved using a muslin cloth and the resulting filtrate was left undisturbed for another 24 hours to allow the starch to settle at the bottom of the bowls to obtain starch slurry. The prepared starch slurry was dried under the sun for one week until a moisture content of $2 \%(\mathrm{wb})$ was achieved. The starch prepared from this cassava cultivar usually contained $16.3 \%$ amylase and $83.7 \%$ amylopectin [17].

\section{Preparation and analyses of zinc nanoparticles}

The sol-gel method, described by Fadeyibi et al. [18], was used to prepare the zinc nanoparticle at the Crop Processing and Storage Laboratory of the Department of Agricultural and Bioresources Engineering, Federal university of Technology, Minna, Nigeria. The method involves the mixture of two homogeneous solutions. The first solution was prepared by adding $30 \mathrm{~mL}$ of distilled water to 20 $\mathrm{mL}$ of triethanolamine with constant stirring while adding $2 \mathrm{~mL}(100$ drops) of ethanol in drop wise. A $5.39 \mathrm{~g}$ of zinc acetate di-hydrate was added to $50 \mathrm{~mL}$ of distil water with continuous stirring, to obtain a 0.5 $\mathrm{M}$ solution, as the second homogeneous solution. The two solutions were mixed together in $500 \mathrm{~mL}$ beaker and a solution of ammonium hydroxide and $10 \mathrm{~mL}$ distilled water was added, in drop wise, with continuous heating and stirring for 20 minutes. Shortly after $30 \mathrm{~min}$, a white bulky solution was formed. It was then washed 8-10 times with distilled water and filtered using a filter paper. The resulting residue was dried in the oven at $95^{\circ} \mathrm{C}$ for $8 \mathrm{~h}$.

The size distribution of the zinc particles was established using the zetasizer equipment (version 7.01) at the Centre of Genetic Engineering and Biotechnology of the Federal University of Technology Minna, Nigeria. The morphology of the zinc particles was studied using Siemens Bruker D5000 Multipurpose X-ray Diffractometer with the CuK a radiation of $1.54 \mathrm{~A}^{\circ}$. This provides information on the intercalation and exfoliation processes of the short-range order of the zinc particles. The test was performed at the Chemistry Laboratory of Sheda Science and Technology Complex (SHESTCO), Abuja, Nigeria.

\section{Development of cassava starch-zinc-nanocomposite film}

The prepared starch from the cassava roots was mixed with the zinc nanoparticles and glycerol in definite proportions to form the different nanocomposites. The ingredients were homogenised with the help of an extruder, dried in an air circulated oven dryer $\left(60^{\circ} \mathrm{C}\right.$ and $80 \%$ $\mathrm{RH})$ for 24 hours and ground to form the nanocomposites, as shown in Figure 1. This was followed by film casting in plastic moulds after adding $600 \mathrm{~mL}$ of distilled water to the nanocomposites and heated at $95^{\circ} \mathrm{C}$.

The plastic mould, designed by determining the surface area using the expression in Equation (1), was used for casting the solution of the starch-glycerol-zinc nanocomposite. The surface area of the mould was $350 \mathrm{~mm} \times 180 \mathrm{~mm}$ and the depth varied as 8,10 and $12 \mathrm{~mm}$. The thickness of the dried film at the four edges of the films was determined using a plastic micrometer, and the average and standard deviation were computed. The plastic mould with $8 \mathrm{~mm}$ depth gave an average

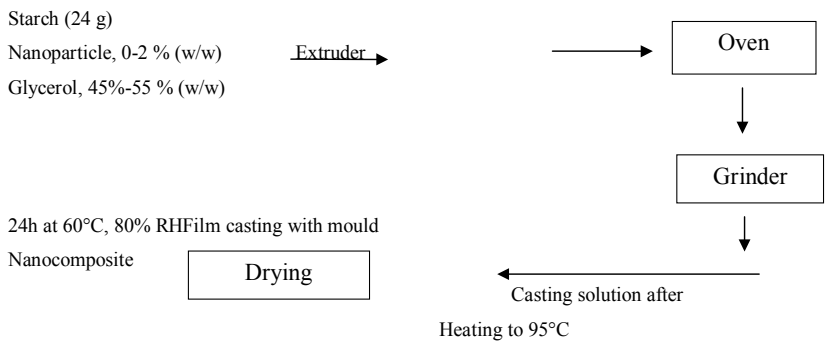

Figure 1: Process flow diagram for the preparation of cassava starch-zinc nanocomposite films.

dried thickness of $15.14 \pm 0.22 \mu \mathrm{m}$, while those with 10 and $12 \mathrm{~mm}$ depths were $16.21 \pm 0.36 \mu \mathrm{m}$ and $17.38 \pm 0.13 \mu \mathrm{m}$, respectively.

$$
T S A=N a+e
$$

Where, $\mathrm{N}=$ number of equivalent biomaterials (500 g), $a=$ surface area of the mould $\mathrm{mm}^{2}, e=$ allowance (assumed $600 \mathrm{~mm}^{2}$ ) and TSA = total surface area of the mould $\left(\mathrm{mm}^{2}\right)$.

\section{Characterisation of the film}

Determination of thermal stability of the film: The thermal stability of the cassava starch-zinc nanocomposite films was determined using the Thermo Gravimetric Analyzer (TGA), at the Centre of Genetic Engineering and Biotechnology of the Federal University of Technology Minna, Nigeria. The chilling compartment of the TGA was initially set at a temperature of $15^{\circ} \mathrm{C}$ to maintain the equipment in the right cooling condition. The temperature scan was also set in the range of $30^{\circ} \mathrm{C}$ to $950^{\circ} \mathrm{C}$ and nitrogen gas was passed into the chambers at a flow rate of $20 \mathrm{~mL} / \mathrm{min}$ and pressure of 2.5 bars for a period of $30 \mathrm{~min}$. The weight of the crucible was zeroed after which a mass $2 \mathrm{mg}$ of the sample was loaded in the TGA thermo-balance, with continuous weighing as heating progresses. Finally the programme was initiated and the weight loss (\%) and time (min) data were measured and recorded as the temperature approached $950^{\circ} \mathrm{C}$. The procedure was repeated thrice for each sample of the cassava starch-zinc-nanocomposite films and the values of the temperature were plotted against the weight loss of the film.

\section{Determination of barrier properties of the film}

Water vapour permeability: The water vapour permeability (WVP) of the nanocomposite films was determined according to the ASTM Standard [19]. The film sample was cut into circle of $4 \mathrm{~cm}$ diameter and placed on petri dish filled with $50 \mathrm{~mL}$ solution of sodium chloride to expose the film to $65 \%$ relative humidity at $25^{\circ} \mathrm{C}$. The petri dish was allowed to equilibrate for two hours before taking the initial weight. The final weight was taken at the end of every one hour. The procedure was replicated three times; and the average of water vapour transmission rate and permeability were determined empirically as expressed in Equations (2) and (3).

$$
\begin{aligned}
& \text { WVTR }=\frac{G}{t A} \\
& W V T=\frac{W V T R}{\Delta p} \times L
\end{aligned}
$$

Where, WVTR $=$ Water vapour transmission rate $\left(\mathrm{g} / \mathrm{s} . \mathrm{m}^{2}\right), \mathrm{WVP}$ = water vapour permeability (g/m.Pa.s), $\mathrm{G}$ is the difference in mass $(\mathrm{g})$, $\mathrm{t}$ is the time (h), and $\mathrm{A}$ is the area of the mouth of the petri dish $\left(\mathrm{m}^{2}\right), \mathrm{L}$ is the thickness of the test specimen $(\mathrm{mm})$ and $\Delta p$ is the partial pressure difference of water vapour across the film. 
Oxygen permeability: The oxygen permeability (OP) of the cassava starch-zinc nanocomposite film was determined empirically using the column absorption method [20]. This was achieved by cutting $1.23 \mathrm{~cm}^{2}$ sample of the film in the absorption column, immersed in a water bath and equipped with a hose from the cylinder containing oxygen gas. The sample was exposed to the oxygen gas, by this arrangement, for a period of one hour at $63 \% \mathrm{RH}$ and $25^{\circ} \mathrm{C}$. The oxygen concentration (\%) in the column was subsequently measured, using an electronic balance ( $0.0001 \mathrm{~g}$ sensitivity) at the end of one hour. The data of properties shown in Table 1 contains the values of some parameters, including an established correlation for the computation of $P_{H 2 O}$ sat , used for the calculation of the oxygen permeability (Table 1 ).

The difference in the partial pressure $(\Delta P)$ was computed using Eqs. (4) to (7).

$$
\begin{aligned}
& {\left[\mathrm{O}_{2}\right]=\frac{{ }^{\mathrm{O}_{2}}}{1000 \mathrm{M}}} \\
& {\left[\mathrm{O}_{2}\right]_{i}=\frac{R H \times P_{\mathrm{H}_{2} \mathrm{O}} \mathrm{sat}}{100 R T}} \\
& {\left[\mathrm{O}_{2}\right]_{t}=\frac{\left[\mathrm{O}_{2}\right]}{\left[\mathrm{O}_{2}\right]_{i}} \times 100 \%}
\end{aligned}
$$

Therefore, $\Delta P_{O_{2}}=\left(\left[O_{2}\right]_{t}-\left[O_{2}\right]_{i}\right) \cdot P_{\text {total }}$

where, $\left[\mathrm{O}_{2}\right]_{\mathrm{t}}$ is the oxygen concentration inside the absorption column at time $t,\left[\mathrm{O}_{2}\right]_{\mathrm{i}}$ is the initial column oxygen content, $m_{o 2}$ is the mass of oxygen gas absorbed by the cassava starch nanocomposite film in the column, $\mathrm{M}$ is the molar mass of oxygen gas $(16 \mathrm{~g} / \mathrm{mol}), \mathrm{R}$ is the molar gas constant $\left(8.31 \times 10^{7} \mathrm{~m}^{3} \mathrm{~Pa} \cdot \mathrm{mol}^{-1} \cdot \mathrm{K}^{-1}\right)$

The total pressure $\left(\mathrm{P}_{\text {total }}\right)$ was calculated by taking into account the influence of the temperature $(T)$ on the saturation pressure of water vapour $P_{\mathrm{H} 2 \mathrm{O}}^{\text {sat }}$ ) and the relative humidity (RH) as shown in Equation (8). The value of OP was subsequently computed from Equation (9).

$$
\begin{aligned}
& P_{\text {total }}=P_{\text {atm }}-P_{\mathrm{H}_{2} O}{ }^{\text {sat }} \cdot R H \\
& O P=\frac{\Delta m \Delta x}{\Delta t A \Delta P O_{2}}
\end{aligned}
$$

The procedure was repeated three times and the oxygen permeability was taken as the average of the oxygen permeability measured under the steady state condition.

Determination of mechanical properties of the film: The nanoindenter was used to determine the mechanical properties of the nanocomposite films. A typical profile of the load-displacement curve of the film, obtained from the nanoindenter, is shown in Figure 2.

The profile was used to compute the hardness, Young's modulus, elastic recovery and creep from the empirical relationships in Equations (10) to (13). The strain was computed as the ratio of the recovered depth to the original depth or thickness of the nanocomposite film. The stress was computed as the product of the strain and the Young's modulus of the material. The elastic and plastic works correspond to

\begin{tabular}{|c|c|}
\hline Parameter & Value \\
\hline Volume of the Column $\left(\mathrm{V}_{\mathrm{v}}\right)$ & $17.42 \times 10^{-3} \mathrm{~cm}^{3}$ \\
\hline Density of Oxygen $\left(\rho_{\mathrm{O} 2}\right)$ & $0.00133 \mathrm{~g} / \mathrm{m}^{3}$ \\
\hline Atmospheric pressure $\left(\mathrm{P}_{\text {atm }}\right)$ & $101325 \mathrm{~Pa}$ \\
\hline Saturated pressure of water vapour $\left(P_{\mathrm{H} 2 \mathrm{O}}{ }^{\text {sat }}\right)$ & $P_{\mathrm{H} 2 \mathrm{O}}{ }^{\text {sat }}=190.2 \mathrm{~T}\left({ }^{\circ} \mathrm{C}\right)-1536.7(\mathrm{~Pa})$ \\
\hline Film area $(\mathrm{A})$ & $1.23 \times 10^{-4} \mathrm{~m}^{2}$ \\
\hline
\end{tabular}

Table 1: Data of properties used for the computation of oxygen permeability.

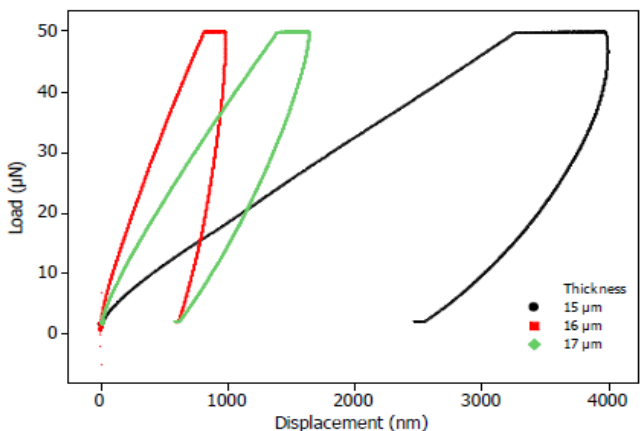

Figure 2: Load-displacement profiles of cassava starch-zinc nanocomposite films at $45 \%(\mathrm{w} / \mathrm{w})$ glycerol and $2 \%(\mathrm{w} / \mathrm{w})$ zinc nanoparticles and different thickness.

the areas under the loading and the unloading parts of the hysteresis loop [21-23].

$$
H=\frac{P_{\max }}{A_{c} h_{c}}
$$

Where, $P_{m x}=$ maximum load, $\mathrm{A}=$ contact area $\left(\mathrm{nm}^{2}\right), \mathrm{h}=$ contact depth $(\mathrm{nm}), \stackrel{\max }{\mathrm{H}}=$ hardness of the nanocomposite film.

$$
\frac{1}{E_{r}}=\frac{1-v^{2}}{E}+\frac{1-v_{i}^{2}}{E_{i}}
$$

where, $E_{r}=$ reduced modulus $(\mathrm{MPa}), \mathrm{v}=$ poison's ratio of the nanocomposite film, which was obtained by assuming that the material is isotropic in nature with the elastic modulus evenly distributed in all crystallographic directions $=0.5, v_{i}=$ poison's ratio of the diamond indenter $=0.25, E_{i}=$ elastic modulus of the diamond indenter $=1140$ $\mathrm{GPa}, \mathrm{E}=$ Elastic modulus of the nanocomposite film.

$$
E R P=\frac{h_{e}}{h_{f}}
$$

Where, $h_{\mathrm{e}}=$ recovered depth $(\mathrm{nm}), \mathrm{h}_{\mathrm{f}}=$ depth of the unloading curve of the profile $(\mathrm{nm}), \mathrm{ERP}=$ elastic recovery parameter.

$\in=\frac{1}{h_{c}} \frac{\mathrm{d} h_{c}}{\mathrm{dt}}$

Where, $\mathrm{h}_{\mathrm{c}}=$ depth at the holding region of the profile $(\mathrm{nm}), \mathrm{t}=$ holding time $(0.5<\mathrm{t}<1), \epsilon=$ strain rate or creep $(\mathrm{nm} / \mathrm{s})$.

\section{Optimisation of the experimental variables of the film}

Development of optimisation framework: The Response Surface Methodology (RSM) was applied to determine the optimum conditions of the experimental variables (concentration of glycerol, zinc nanoparticles and thickness) based on the characterised attributes of the films, namely mechanical, barrier and thermal properties. A Box-Behnken Design (BBD), which includes 17 experiments formed by 5 central points, was employed in the optimization process because of its suitability for a $3^{3}$ full factorial experiment. The optimization framework of the BBD protocol is shown in Equation (14).

$$
\begin{aligned}
& \forall \Phi=f\left(X_{1}, X_{2}, X_{3}\right)+e, \text { subject to the constraints: } \\
& \left\{\begin{array}{c}
15 \leq X_{1} \leq 17 \mu m \\
45 \leq X_{2} \leq 55 \% \\
0 \leq X_{3} \leq 2 \%
\end{array}\right.
\end{aligned}
$$

Where, $\Phi=$ characterised attributes of the film (barrier, thermal, mechanical properties), $X_{1}=$ thickness of the film, $X_{2}=$ concentration 
of glycerol, $X_{3}=$ concentration of zinc nanoparticles, $e=$ error term of the optimisation function.

Desirability function: Desirability is an objective function that ranges from zero outside a limit to one at the goal. It is possible to alter the characteristics of a goal by either maximizing or minimizing the optimisation function. For several responses and factors, all goals can be combined into one desirability function [24]. Therefore, in this study the objective functions are to maximise the mechanical properties and minimise the permeability and thermal stability of the films. The reason for the choice of a particular objective function is centered on the need to select the most desirable film, whose characteristic feature is comparable to the conventional low density polyethylene material.

\section{Results and Discussion}

\section{Establishment of zinc nanoparticles}

The results of the size distribution of the zinc particles were shown in Figure 3. It can be seen that the size of the zinc particles are heterogeneous as it varied in the range of $4 \mathrm{~nm}-9 \mathrm{~nm}$. The variation in the size of the zinc particles can be associated with the increase in their solubility in the water used as solvent [25]. Tang et al. [26] revealed that organic or inorganic particles having their particle size in the range of 1-100 $\mathrm{nm}$ can be regarded as nanoparticles, especially when used for food packaging application (Figure 3).

Moreover, Figure 4 showed the X-ray diffraction pattern of the zinc particles. The diffraction peaks obtained confirmed the presence of the heterogeneous structure of the zinc nanoparticles. It is possible that the galleries of the zinc nanoparticles are forced apart during the irradiation process thus leading to an increase in the gallery spacing (d-spacing) [27]. According to Bragg's law, this would cause a shift in the diffraction peak towards a lower angle. The peak, at the lower angle, becomes wider and finally broadens into the base line; thus revealing a complete heterogeneous structure. Similar behaviours have been observed for montmorilonite, which shows complete heterogeneous structure by the presence of distinct diffraction peaks $[26,28]$. The use of the zinc nanoparticles can help improve the performance of the film for food packaging application (Figure 4).

\section{Thermal stability of the film}

The thermal degradation curves of the cassava starch-zinc

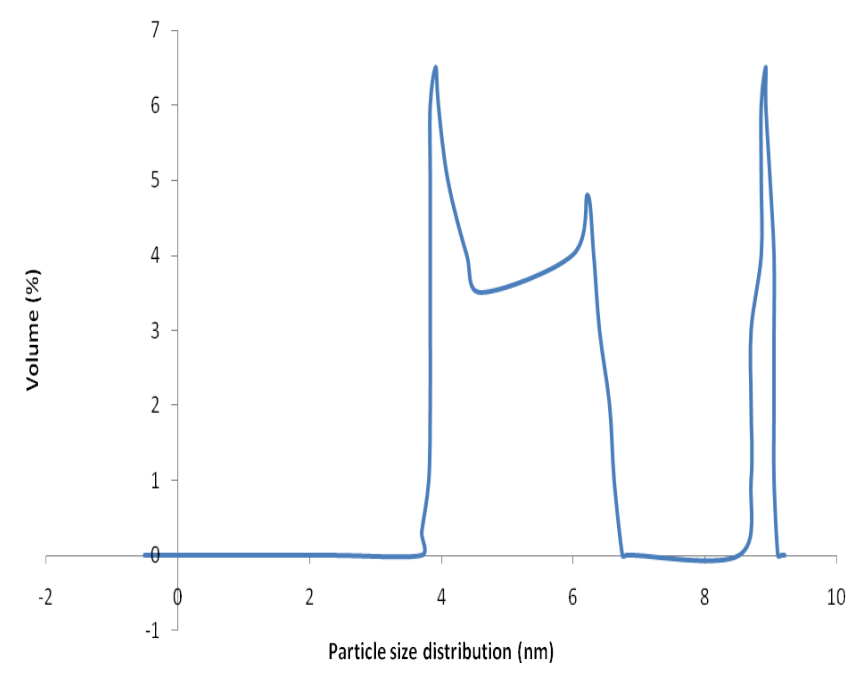

Figure 3: Size distribution of zinc nanoparticles.

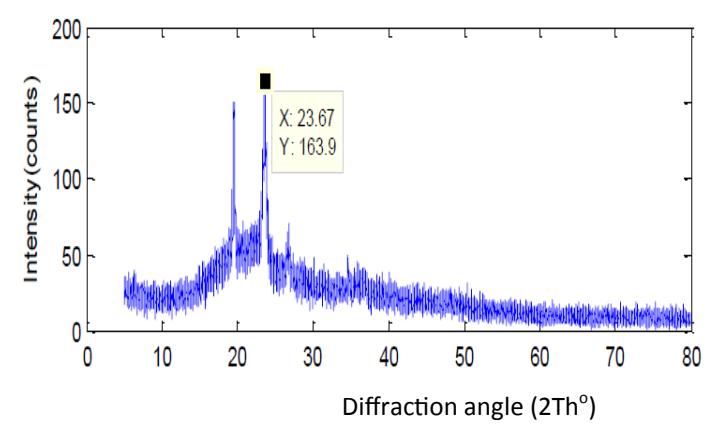

Figure 4: XRD pattern of the zinc nanoparticles.

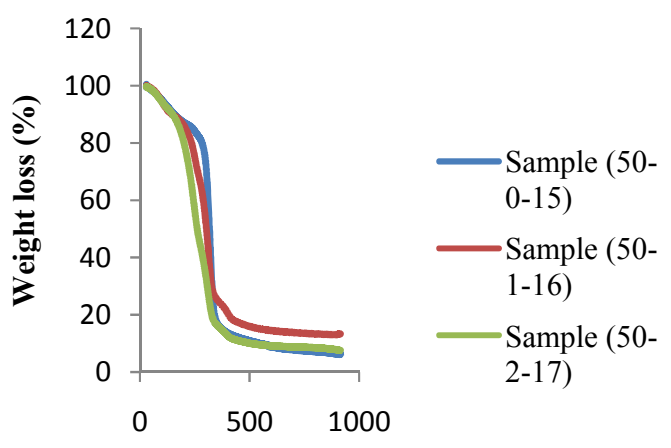

Degradation temperature (deg C)

Figure 5: Effect of experimental variables on thermal stability of the films.

nanocomposite films are typically shown in Figure 5. It can be seen that the thermal decomposition of the films occurred in three main steps, which generally conforms to the three thermal degradation phenomena of most starch-based films reported in literature [29-31]. The initial stage of the thermal degradation of the films occurred at temperature less than $100^{\circ} \mathrm{C}$. The weight loss of the cassava starch-zinc nanocomposite films at this stage are in the range of $2 \%$ to $3 \%$, and can be associated with the evaporation or dehydration of loosely bound water molecules and low molecular weight compounds in the films. The cassava starch-zinc nanocomposite films show higher mass loss at $50 \%$ glycerol concentration and $15 \mu \mathrm{m}$ thickness compared with the 17 $\mu \mathrm{m}$ counterparts at temperature lower than $100^{\circ} \mathrm{C}$. This indicates that the films with $50 \%$ glycerol concentration and $0 \%$ zinc nanoparticles contain moisture than the ones with $50 \%$ glycerol concentration and $2 \%$ zinc nanoparticles. The second stage of the thermal degradation of the films ranges from $150^{\circ} \mathrm{C}$ to $260^{\circ} \mathrm{C}$, which corresponds with the evaporation of glycerol compounds together with chemisorbed water molecules (Figure 5).

The degradation temperatures of the films agree with the findings of Zhong and Li [15] and Sanyang et al. [32] who reported the degradation temperature of glycerol-rich phase of kudzu starch-based edible films and biodegradable films based on sugar palm starch between $150^{\circ} \mathrm{C}$ to $280^{\circ} \mathrm{C}$ and $120^{\circ} \mathrm{C}$ to $290^{\circ} \mathrm{C}$, respectively. Further heating beyond $260^{\circ} \mathrm{C}$ induced the highest thermal degradation rate which is reflected by the sharp weight reduction of the films. The onset of thermal decomposition of starches occurred at the residual weight, which is around $300^{\circ} \mathrm{C}$ for the films. According to Nescimonto et al. [33], this stage corresponds to the elimination of hydrogen groups, decomposition and depolymerisation of starch carbon chain. Generally, the residual weights represent almost complete decompositions of the films since more than $80 \%$ of the films 
have been degraded. Beyond this temperature range, the films become unstable and the weight loss of the films increased with an increase in temperature. Similar degradation responses with temperature change were obtained for other thicknesses and concentrations of glycerol and zinc nanoparticles, as was shown in Figure 5. It can be argued that the increase concentrations of the glycerol and the zinc nanoparticles are partly responsible for the slight difference in the three stages of decomposition of the films. The comparison of the behaviour of the cassava starch-zinc-nanocomposite film with that of the low density polyethylene material (LDPE) revealed that the thermal stability of the film is lower than the LDPE. According to Chatloff and Sircar [34], a single mass degradation step, occurring at $478^{\circ} \mathrm{C}$, has often been observed for LDPE and other synthetic polymers. This is in sharp contrast to the thermal degradation behaviour of the cassava starch nanocomposite films, which revealed three mass degradation stapes. This study provides a fair knowledge about the thermal stability of the films for potential application in food packaging.

\section{Permeability of the films}

The influence of the experimental variables (thickness, concentration of glycerol and zinc nanoparticles) on the average values of the water vapour permeability is shown in Figure 6. It can be seen that the water vapour permeability increased generally with increase in the concentrations of the glycerol, zinc nanoparticles and thickness. This means that the experimental variables played significant roles in promoting the water vapour permeability of the resulting nanocomposite material. The presence of zinc nanoparticles together with increased thickness of the material help create a composite matrix with higher water absorption ability [30,34-36]. The reason for the increase in the water vapour permeability of the films with increasing concentration of the nanoparticles could be explained by structural modifications of the composite matrix, which may result from the high surface area to volume ratio of the nanoparticles. Thus, in order to maintain the quality of agricultural produce, it is necessary to package the food in a material with high water permeability (Figure 6).

The influence of the experimental variables on the oxygen permeability of the nanocomposite films is shown in Figure 7. The oxygen permeability decreased with increasing thickness and concentrations of glycerol and zinc nanoparticles. It is possible that the presence of the nanoparticles restricted the mobility of the gas molecules as they diffuse across the films. The mobility was altered

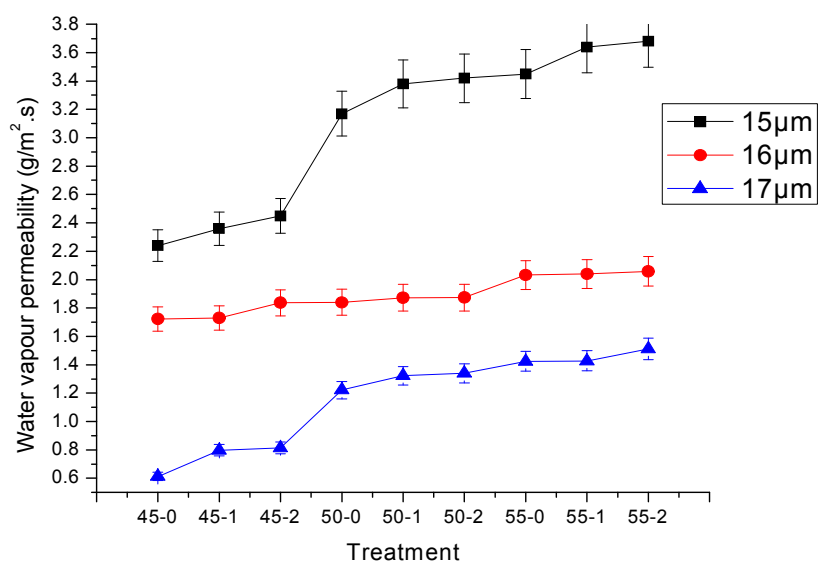

Figure 6: Effects of experimental variables on water vapour permeability of the films.

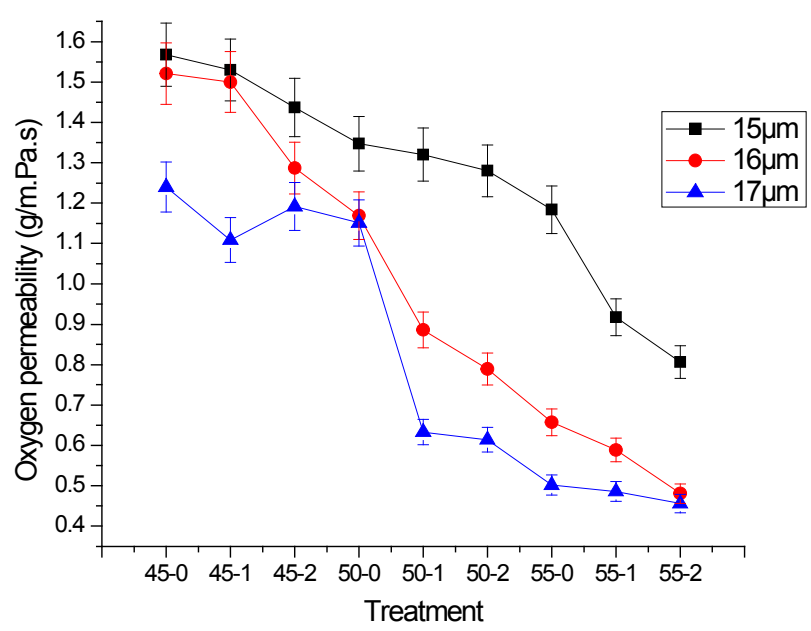

Figure 7: Effects of experimental variables on oxygen permeability of the films.

with the increase in the concentration of the nanoparticles, which is associated with their scavenging potential and the decreasing porosity of the composite matrix. It is important to note that, lower gas permeability of the films is an advantage in the nanocomposite technology, especially when they are to be used for packaging purposes. Therefore, by this action, the nanocomposite films can be regarded as an active or intelligent packaging material.

\section{Mechanical properties of the films}

The effects of thickness and zinc nanoparticles on the mechanical properties of the nanocomposite films are shown in Figures 8 and 9. The creep, which is essential in determining the strain rate sensitivity of the nanocomposite material, decreased with nanoparticles and thickness of the film. The hardness of the material decreased with thickness and zinc nanoparticles. The Young's modulus and elastic recovery parameter increased with nanoparticles but their behaviours were found to be inconsistent with thickness of the films, as shown in Figure 8. These behaviours can be attributed to the increased displacement of the film with a slight change in the applied load as the thickness increased.

The elastic and plastic works, which determine the plasticity index of the materials, generally decreased with thickness and zinc nanoparticles, as shown in Figure 9. This means that the higher the concentration of the nanoparticles and thickness, the lower the plasticity index and thus the viscoelastic behaviour of the resulting nanocomposite material. The strain and stress of the material decreased generally with thickness and nanoparticles. This may be associated with the increasing area of contact of the diamond indenter with the applied load. Jorge et al [36] corroborated our findings in their work on the mechanical properties of gelatin-montmorillonite nanocomposite film. The presence of montmorilonite increased the mechanical properties of the film. Hence, the nanoparticles be said to contribute in the improvement of the mechanical properties of the nanocomposite material due probably to their large surface area to volume ratio.

\section{Optimally selected films}

The optimum values of the permeability due to oxygen and water vapour of the nanocomposite films, which were determined by minimising the responses subject to the defined constraints of the experimental variables, is shown in Figure 10. The desirability function 

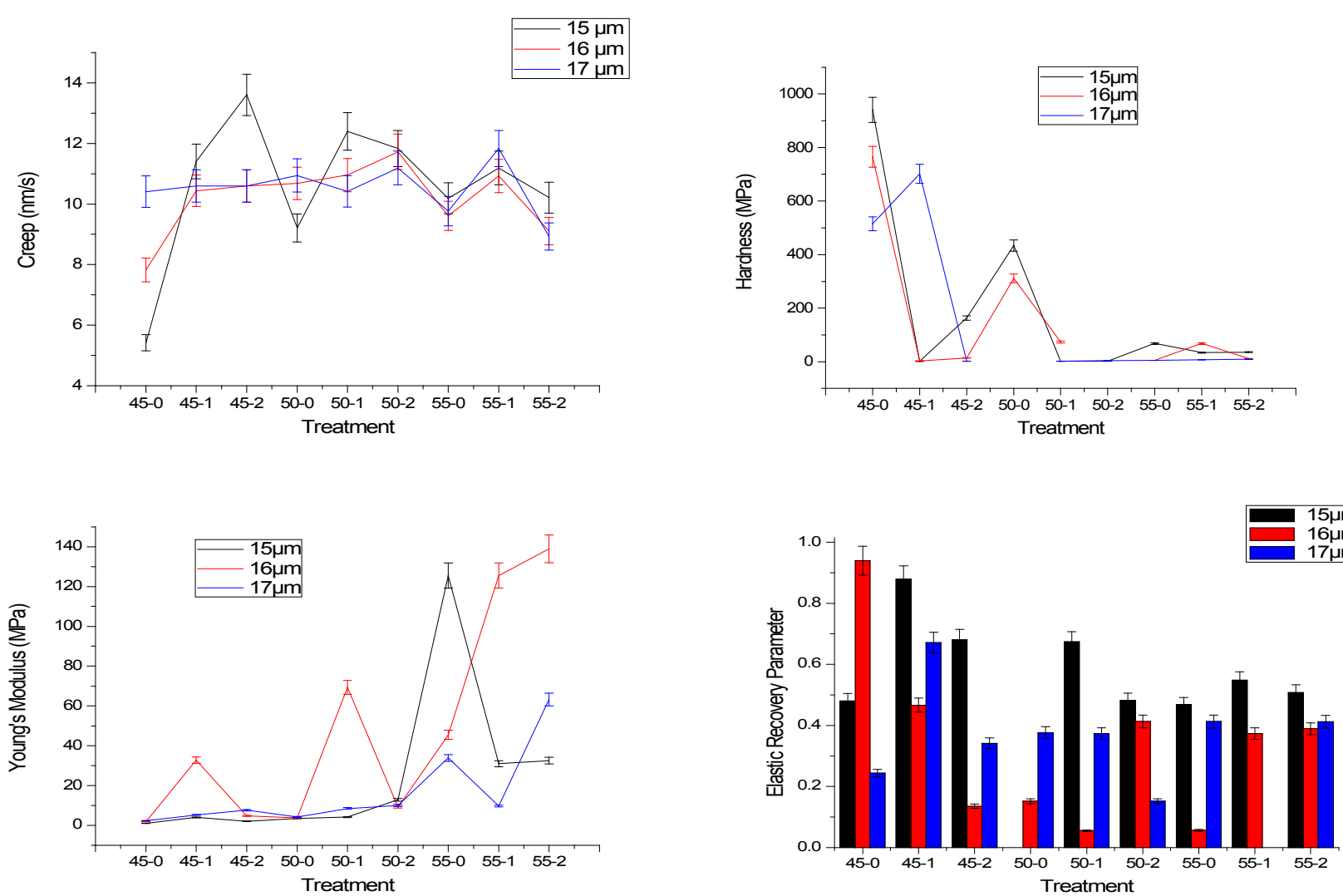

Figure 8: Effect of experimental variables on creep, hardness, Young's modulus, elastic recovery parameter of the films.
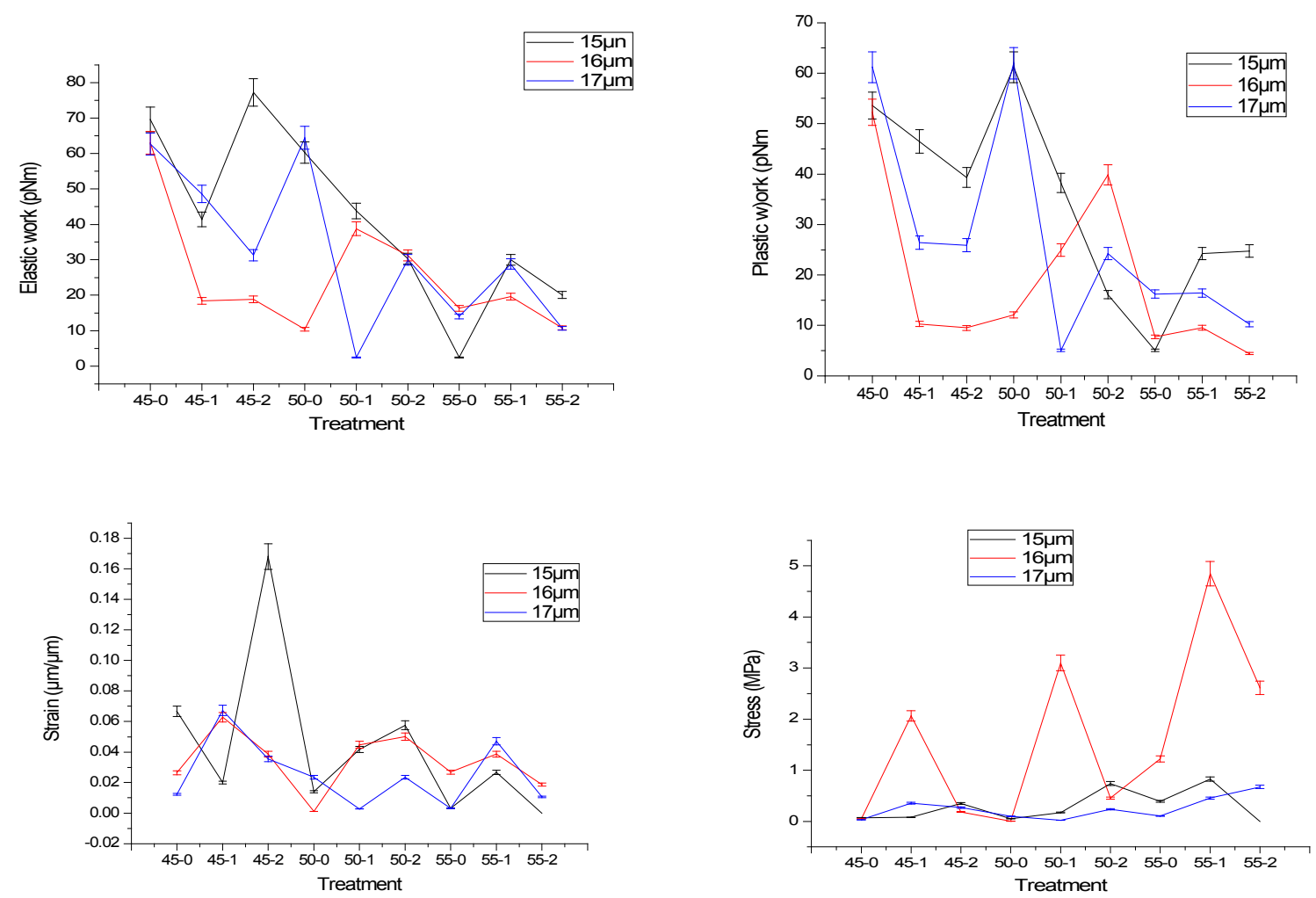

Figure 9: Effects of experimental variables on strain, stress, elastic and plastic works of the films. 
of selecting the best combination of the experimental variables increased with thickness but decreased with the concentration of the glycerol regardless of the concentration of the zinc nanoparticles. The increased desirability may also be associated with the degree of the interaction among the experimental variables. Similarly, selecting the films based on their thermal stability also required higher degree of interaction among the experimental variables, as shown in Figure 11. It can be deduced from these observations that higher thickness and lower glycerol concentration will greatly influence the solution goals, which are to minimise the permeability and maximise the thermal stability (Figures 10 and 11).

Additionally, the optimum film was selected based on the desirability of obtaining the maximum mechanical response, as shown in Figure 12. The desirability, in this case, was mainly influenced by the effective contribution of the interaction among the experimental variables on the overall acceptability of the solution goal. The individual contributions of the variables were lesser compared to their associated interaction. Hence, the optimum film whose desirability function is closer to the solution goals gave values of $49.29 \%$ glycerol, $17 \mu \mathrm{m}$ thickness and $2 \%$ zinc nanoparticles. The matrix of the ideal film, by implication, should be made of these values for better service performance with respect to the characterised attributes of the films (Figure 12).
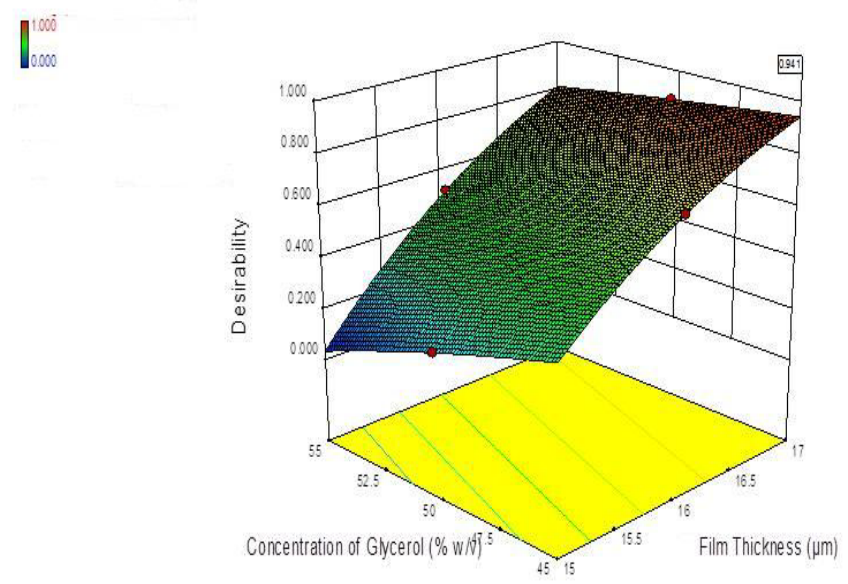

Figure 10: Surface response desirability for oxygen and water vapour permeability of the films.

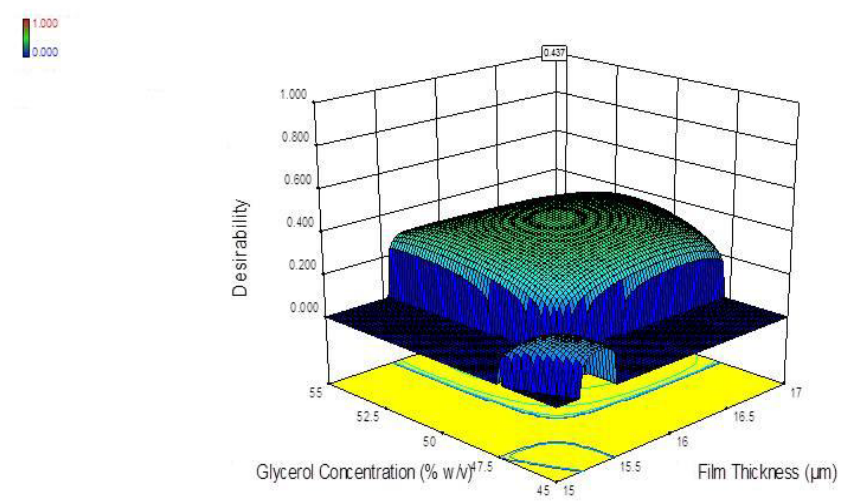

Figure 11: Surface response desirability for mechanical properties of the films.

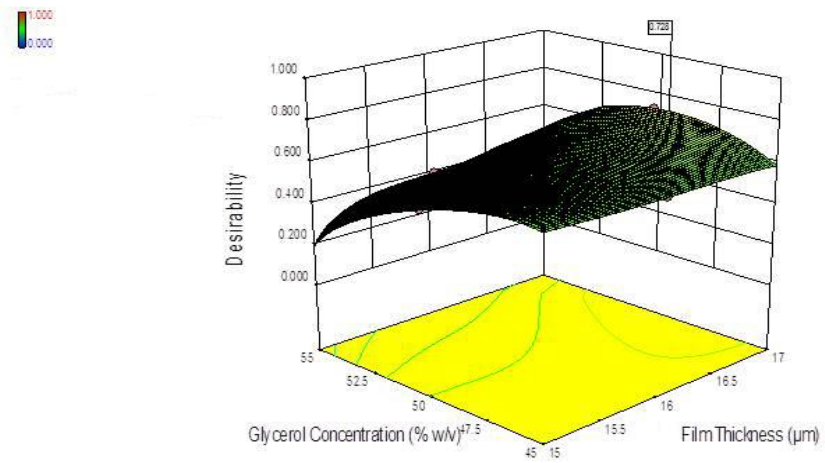

Figure 12: Surface response desirability for thermal stability of the films.

\section{Conclusion}

The food industry has seen great advances in the packaging sector with many innovations occurring lately. These advances have led to improved food quality and safety. This research was undertaken to develop and optimize the cassava starch-zinc-nanocomposite films for potential application in food packaging. The films were found to be thermally stable with $2 \%$ to $3 \%$ of their weights degraded below $100^{\circ} \mathrm{C}$. The water vapour permeability increased while the oxygen permeability decreased with the concentration of glycerol, zinc nanoparticles and thickness of the films. The mechanical properties decreased generally with the thickness and zinc nanoparticles. The optimum film whose desirability function is closer the optimisation goal gave values of $49.29 \%$ glycerol, $17 \mu \mathrm{m}$ thickness and $2 \%$ zinc nanoparticles for maximum thermal stability and mechanical properties. The lower gas permeability of cassava starch-zinc nanocomposite film can slow down the rate of respiration, just as the higher water vapour permeability can promote the keeping quality especially in packaged foods. It is likely that the oxygen scavenging effect of the zinc nanoparticles, which can retard ripening, senescence and consequent deterioration, may be responsible for the low gas permeability of the new packaging material. It can be deduced from the behaviour of the nanocomposite film that it has potential application in food packaging.

\section{Acknowledgement}

The authors would like to thank the Tertiary Education Trust Fund (TETFund) of the Federal Ministry of Education, Nigeria and the management of the Federal University of Technology, Minna, Nigeria for providing the grant (TETFUND/DESS/ RP.DIS/FUT/MINNA/VOL.XV) and work space for carrying out this research.

\section{References}

1. Duncan TV (2011) Applications of nanotechnology in food packaging and food safety: Barrier materials, anti-microbials and sensors. J Coll Int Sci 12: 34-40.

2. Mehyar GF, Han JH (2004) Physical and mechanical properties of high-amylose rice and pea starch films as affected by relative humidity and plasticiser. J Food Sci 69: 449-459.

3. Tharanathan RN (2003) Biodegradable films and composite coatings: past, present and future. Trends Food Sci Tech 14: 71-78.

4. Kirwan MJ, Strawbridge JW (2003) Plastics in food packaging. Food Pack Tech 1: $174-240$.

5. Lagaron JM, Sanchez-garcia M (2008) Thermoplastic nanobiocomposites for rigid and flexible food packaging applications, In: E. Chiellini (ed.) Environmentally friendly food packaging, FL pp. 62-89, Woodhead Publishers, Boca Raton

6. Azeredo HMC (2009) Nanocomposites for food packaging applications. Food Res Int 42: 1240-1253.

7. Hernandez R, Selke SEM, Cultler J (2000) Plastics packaging: properties 
Citation: Fadeyibi A, Osunde ZD, Agidi G, Idah PA, Egwim EC (2016) Development and Optimisation of Cassava Starch-Zinc-Nanocomposite Film for Potential Application in Food Packaging. J Food Process Technol 7: 591. doi:10.4172/2157-7110.1000591

processing, applications, regulations. Hanser Gardner Publications, Munich, Germany.

8. Adams LK, Lyon DY, Alvarez PJJ (2006) Comparative eco-toxicity of nanoscale $\mathrm{TiO}_{2}, \mathrm{SiO}_{2}$, and $\mathrm{ZnO}$ water suspensions. Water Res 40: 3527-3532.

9. Jones N, Ray B, Ranjit KT, Manna AC (2008) Anti-bacterial activity of ZnO nanoparticle suspensions on a broad spectrum of microorganisms. FEMS Microbiol Lett 279: 71-76.

10. Emamifar A, Kadivar M, Shahedi M, Solaimanianzad S (2011) Effect of nanocomposite packaging containing $\mathrm{Ag}$ and $\mathrm{ZnO}$ on inactivation of Lactobacillu splantarum in orange juice. Food Control 22: 408- 413

11. Zeng QH, Yu AB, Lu GQ, Paul DR (2005) Clay-based polymer nanocomposites: research and commercial development. J Nanosci Nanotech 5: 1574-1592.

12. Taghizadeh MT, Sabouri N (2013) Thermal degradation behaviour of polyvinyl alcohol/starch/carboxymethyl cellulose/ clay nanocomposites. Univer J Chem 1: 21-29.

13. Huang MF, Yu JG (2006) Structure and properties of nanocomposites and their characteristics, Carbohydrate composites. J App Poly Sci 99: 170-176.

14. Zhang L, Jiang $Y$, Ding $Y$ (2008) ZnO nanofluids-A potential anti-bacterial agent. Prog Nat Sci 18: 939-944.

15. Zheng JP, Li P, Ma YL, Yao KD (2014) Gelatine/montmorillonite hybrid nanocomposite. I. Preparation and properties. J Appl Poly Sci 86: 1189-1194.

16. Dang KM, Yoksan R (2015) Development of thermoplastic starch blown by incorporating plasticized chitosan. Carbohydrate Polymers 115: 575-581.

17. Dakubu M, Bruce-smith SP (1979) Amylose content of starch from different varieties of cassava (Manihot esculenta crantz) in Ghana. Ghana J Agri Sci 12: $143-145$.

18. Fadeyibi A, Osunde ZD, Agidi G, Evans EC (2016) Mixing index of a starch composite extruder for food packaging application. In: Inamuddin S (ed.) Green polymer composites technology: properties and applications. CRC press and Taylor and Francis Group, Asia Pacific.

19. Astm Standards (2005) E96-05 Standard test methods for water vapour transmission of materials. Philadelphia, PA.

20. Laksmana FL, Hartman Kok PJA, Frijlink HW, Vromans H, Voort Maarschalk $\mathrm{K}$ (2009) Gas permeation related to the moisture sorption in films of glassy hydrophilic polymers. J Appl Poly Sci 5: 1-10.

21. Syed VA, Nagamani H, Yeshwanth A, Sundaram S (2013) Nano-indentation behaviour of ultrathin polymeric films. Adv Aero Sci Appl 3: 235-238.
22. Tall PD, Ndiaye S, Beye AC, Zong Z, Soboyejo WO, et al. (2007) Nanoindentation of Ni-Ti thin films. Mat Manu Pro 22: 175-179.

23. Jian S, Chen G, Hsu W (2013) Mechanical properties of $\mathrm{Cu}_{2} \mathrm{O}$ thin films by nanoindentation. Materials 6: 4505-4513.

24. Vargas-Lopez JM, Paredes-Lopez O, Espitia E (2006) Evaluation of lime hea treatment on physicochemical properties of amaranth by response surface methodology. Cereal Chem 67: 417- 421.

25. Makhluf S, Dror R, Nitzan Y, et al. (2005) Microwave-assisted synthesis of nanocrystalline $\mathrm{MgO}$ and its use as bacteriocide. Adv Funct Mat 15: 1708-1715.

26. Tang X, Alavi S, Herald TJ (2008) Effects of plasticizers on the structure and properties of starch-clay nanocomposite films. Carbohydrate Poly 74: 552-558.

27. Mcglashan SA, Halley PJ (2003) Preparation and characterization of biodegradable starch-based nanocomposite materials. Poly Int 52: 1767-1773.

28. Chung Y, Ansari S, Estevez L, Hayrapetyan S, Giannelis EP, et al. (2010) Preparation and properties of biodegradable starch-clay nanacomposites. Carbohydrate Poly 79: 391-339.

29. Dang KM, Yoksan R (2015) Development of thermoplastic starch blown by incorporating plasticized chitosan. Carbohydrate Poly 115: 575-581.

30. Sanyang ML, Sapuan SM, Jawaid M, Ishak MR, Sahari J, et al. (2015) Effect of plasticiser type and concentration on tensile, thermal and barrier properties of biodegradable films based on sugar palm (Arenga pinnata) starch. Polymers 7: 1106-1124.

31. Mehyar GF, Han JH (2014) Physical and mechanical properties of high-amylose rice and pea starch films as affected by relative humidity and plasticiser. J Food Sci 69: 449-459.

32. Nascimento TA, Calado V, Carvalho CWP (2012) Development and characterisation of flexible film based on starch and passion fruit mesocarp flour with nanoparticles. Food res int 49: 588-595.

33. Chatloff RP, Sircar AK (2007) Thermal analysis of polymers. Encyclopedia of polymer science and Technology, John Wiley and Sons.

34. Dai L, Qui C, Xiong L, Sun Q (2015) Characterisation of corn starch-based films reinforced with taro starch nanoparticles. Food Chem 174: 82-88.

35. Rojas-graü M, Tapia M, Martín-belloso O (2008) Using polysaccharide-based edible coatings to maintain quality of fresh-cut fuji apples. U-Technology 41 139-147.

36. Jorge MFG, Vanin FM, de Carvalho RA, Moraes ICF, Bittante AMQB, et al. (2014) Mechanical properties of gelatin nanocomposite films prepared by spreading: effect of montmorillonite concentration. 